\title{
BRINCADEIRAS E LITERATURA: EXPERIÊNCIA DE TRABALHO E POSSIBILIDADES DE ENSINO NO BERÇÁRIO ${ }^{1}$
}

\author{
PEREIRA, Raquel Quintina² \\ RODRIGUES, Vânia Ramos ${ }^{3}$
}

\section{RESUMO}

Este trabalho é resultado de uma experiência realizada na disciplina de Estágio em Educação Infantil (EI) e anos iniciais do Ensino Fundamental II em uma instituição de ensino da cidade de Jataí - GO. O trabalho foi desenvolvido por meio de um projeto de intervenção em uma turma do Berçário I, na qual buscamos conhecer e compreender possibilidades de trabalho com crianças entre quatro meses e um ano e meio de idade. Sendo assim, levantamos a seguinte questão: é possível trabalhar com crianças dessa faixa etária, garantindo que a instituição seja espaço de cuidado, brincadeira e educação? É também possível trabalhar com a literatura infantil como garantia de aprendizagem na EI? Este trabalho tem como objetivo incentivar e propiciar o desenvolvimento das habilidades físico/motora, afetiva, cognitiva, ética, estética, social, interpessoal dos bebês, por meio da brincadeira e literatura infantil. Utilizamos estudo bibliográfico a partir dos aportes teóricos de Abramovich (1997), Arce e Silva (2009), Lino (1999), Horn (2004), dentre outros. Concluímos nossa proposta cientes da grande importância de uma parceria ativa e eficaz entre a universidade e as instituições de ensino, no sentido de aliar às teorias que embasam o trabalho na prática e de que quando levamos à instituição os nossos conhecimentos, é no intuito de ali propor diferentes possibilidades de desenvolvimento da criança de berçário, mostrando possibilidades de ensino e desconstruindo um conceito de que a creche não é apenas um lugar para se cuidar das crianças ${ }^{4}$, deixando claro que até mesmo nas atividades de rotina, podemos passar ensinamentos e desenvolver o cognitivo das crianças.

Palavras-chave: Educação Infantil. Brincadeiras. Literatura.

\footnotetext{
${ }^{1}$ Trabalho apresentado como forma de comunicação oral no XXVII Congresso de Educação do Sudoeste Goiano (CONADE) 2013 - Trabalho e Educação: formação do trabalhador e do educador.

${ }^{2}$ Graduada em Pedagogia pela Universidade Federal de Goiás (UFG) - Regional Jataí. Email: raquelqpb@gmail.com.

${ }^{3}$ Graduada em Pedagogia pela Universidade Federal de Goiás (UFG) - Regional Jataí. Email: vaniaramosr@gmail.com.

${ }^{4}$ Maiores informações sobre este assunto consultar: LIMA, Laís Leni O. As muitas faces do trabalho que se realiza na educação infantil. Tese (Doutorado em Educação) - Faculdade de Educação, Universidade Federal de Goiás, Goiânia, 2010.
} 


\title{
CHILD PLAYS AND LITERATURE: WORK EXPERIENCE AND POSSIBILITIES OF EDUCATION IN NURSERY
}

\begin{abstract}
This paper is the result of an experiment carried out in the subject Internship in Early Childhood Education (CE) and initial years of primary school II in an educational institution in the city of Jataí - GO. The work was developed through an intervention project in a class of Nursery I, in which we sought to know and understand work opportunities with children between four months and a year and half old. Therefore we have raised the question: is it possible to work with this age group, ensuring that the institution is a space of care, fun and education? It is also possible to work with children's literature as a learning assurance in CE? This paper aims to encourage and promote the development of physical/motor skills, affective, cognitive, ethical, aesthetic, social and interpersonal in babies, through games and children's literature. We used a bibliographic study from the theoretical contributions of Abramovich (1997), Arce and Silva (2009), Lino (1999), Horn (2004), among others. We concluded our proposal aware of the importance of an active and effective partnership between universities and educational institutions in order to combine the theories that support the work in practice and that when we take our knowledge to institutions is on the intention of propose different nursery child's development possibilities, showing educational possibilities and deconstructing a concept that childcare is not just a place to care for children, making it clear that even in routine activities, we can teach and develop the cognition in children.
\end{abstract}

Keywords: Childhood Education. Child Plays. Literature.

\section{INTRODUÇÃO}

Este trabalho é resultado de experiência por meio de um projeto de intervenção-ação da disciplina de Estágio em Educação Infantil e anos iniciais do Ensino Fundamental II, intitulado "Corpo e movimento: uma 'pitada' de literatura infantil"5, proposto em uma turma do Berçário I, a qual compreendia crianças de quatro meses a um ano e meio de idade. O presente trabalho tem como objetivo mostrar como podemos incentivar e propiciar o desenvolvimento das habilidades físico/motora, afetiva, cognitiva, ética, estética, social, interpessoal dos bebês, por meio da brincadeira e literatura infantil.

\footnotetext{
${ }^{5}$ Trabalho realizado em uma Instituição pública de Educação Infantil no primeiro semestre de 2012.
} 


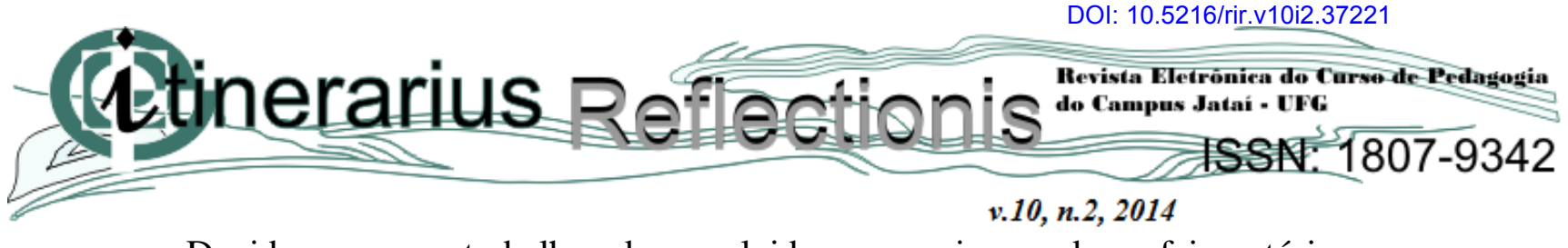

Devido a poucos trabalhos desenvolvidos com crianças dessa faixa etária e a carência de estímulos propostos, é que propomos a relevância da pesquisa sobre o referido tema. Durante o Estágio de Observação na instituição, na qual propomos o projeto de intervenção-ação, percebemos algumas possibilidades de trabalho diferenciado com os bebês, tanto na sala como no próprio pátio da instituição.

Nossa proposta de trabalho se baseou nas atividades de música, literatura infantil, brincadeiras e alguns tipos de texturas. Estas atividades foram desenvolvidas a fim de trabalharmos o desenvolvimento afetivo das crianças, o relacionamento entre seus pares bem como com as educadoras. Pretendíamos conhecer como os bebês percebiam e eram estimulados ao conhecimento de mundo que os rodeiam.

Julgamos importante apoiar-nos em Arce e Silva (2009) para, à luz de seus ensinamentos, fundamentar a importância da mediação do adulto na socialização das crianças pequenas afirmando que:

\begin{abstract}
as primeiras relações sociais travadas pelo bebê são mediadas pelos adultos que cuidam dele, que introduzem e apresentam o mundo no qual ele irá viver. Este movimento é complexo e intenso, pois o adulto torna-se responsável pela formação de hábitos nas crianças; por exemplo, o próprio paladar da criança é formado com a mediação dos adultos por meio dos alimentos a ela oferecidos. A criança está totalmente aberta ao mundo e seus sabores, cheiros, barulhos e é o adulto que desvela este universo confuso para ela (p. 165).
\end{abstract}

Nessa fase as crianças ainda são muito dependentes dos adultos, por isso é importante saber identificar as necessidades das crianças, pois as mesmas ainda não têm o domínio da fala, e sua comunicação acontece basicamente por meio dos seus gestos e movimentos corporais. O papel do professor nessa etapa da vida da criança é contribuir para o desenvolvimento do bebê, seja da comunicação, do movimento do corpo, afetividade, socialização e ainda do desenvolvimento cognitivo.

\title{
2. OBJETIVOS
}

- conhecer e compreender possibilidades de trabalho com crianças entre quatro meses e um ano e meio de idade; 


\section{(ctinerarius Reflectionis

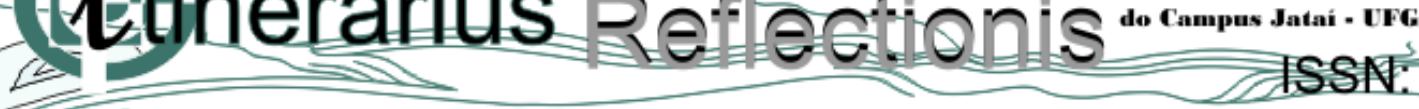 \\ v.10, n.2, 2014}

- incentivar e propiciar o desenvolvimento das habilidades físico/motora, afetiva, cognitiva, ética, estética, social, interpessoal dos bebês, por meio da brincadeira e literatura infantil.

\section{METODOLOGIA E FUNDAMENTAÇÃO TEÓRICA}

A instituição de educação infantil é um lugar onde o pedagógico acontece, pensando assim é importante oportunizar diferentes atividades para as crianças a fim de que o trabalho pedagógico realmente aconteça, e ainda garantir uma intervenção de qualidade às crianças.

Apresentaremos a seguir, algumas propostas de trabalho realizadas em uma turma de Berçário I da Educação Infantil, com atividades nas quais envolviam músicas, literatura infantil, brincadeiras, texturas com o intuito de favorecer o desenvolvimento pleno dos bebês.

Para desenvolver este trabalho inicialmente recorremos ao Projeto e Relatório de Estágio realizado na instituição de EI no qual propusemos a intervenção-ação. Utilizamos de alguns aportes teóricos para embasar a nossa prática, tais como: Abramovich (1997), Arce e Silva (2009), Lino (1999), Horn (2004) e de outros relacionados ao trabalho específico com a Educação Infantil.

A primeira proposta de intervenção na instituição de ensino foi trabalhar com música e literatura infantil. Ao chegarmos à turma do Berçário I, de início o nosso objetivo era interagir com as crianças com o auxílio da música. Esse momento era muito especial, pois algumas crianças ainda choravam quando eram deixadas na instituição pelos pais. A música nos auxiliava em vários momentos, desde a chegada até o momento do banho. As crianças gostaram muito. Nesse momento elas pulavam, dançavam e até soltavam frases completas. Nesse momento, estabelecemos com elas um momento muito especial, pois surgiram abraços, carinhos e até uma roda pôde ser formada.

De acordo com Lino (1999):

A relação afetivo-sonora [...] é de vital importância, não só pelo grande valor humano, mas também por ser um meio de comunicação diferente, ao passo que 


\section{(1ttinerarius Refloctionis

também pode detectar possíveis problemas de ordem auditiva na criança. Outrossim, apontamos que apesar de nem sempre o bebê responder à realimentação sonora, ele vai criando um espectro de imagens auditivas que fazem parte de sua musicalidade (p. 72).

Após a acolhida das crianças e o momento das mamadeiras, objetivamos o desenvolvimento da oralidade por meio do uso da literatura. Neste momento, ficamos sentadas no tapete do chão da sala, colocamos uma caixa de papelão no chão a qual continha dezenas de livros literários. E quando abrimos e mostramos às crianças todos aqueles livros, elas ficaram encantadas. Logo já começaram as escolhas atentando para as imagens. Algumas crianças até já conheciam certas imagens, pois apontavam o dedo e diziam alguma coisa relacionada àquela imagem, como por exemplo: falavam "có có" quando viam uma galinha; "au au" e apontavam para o cachorro, além de muitos outros. Esse momento foi significativo, pois percebemos ali os conhecimentos prévios que as crianças já obtinham e também tivemos a possibilidade de propiciar outros a elas.

Nesse dia, levamos livros com diversos tipos de histórias e imagens. Imagens de natureza, vários tipos de animais, gente adulta e crianças. A dificuldade foi contar a história até o final, pois diante de tanta opção as crianças queriam ver e manusear todos ao mesmo tempo, conforme nos mostram a imagem da ilustração 1. A identificação das crianças nas imagens, que seguem, foi suprimida para preservar suas identidades.

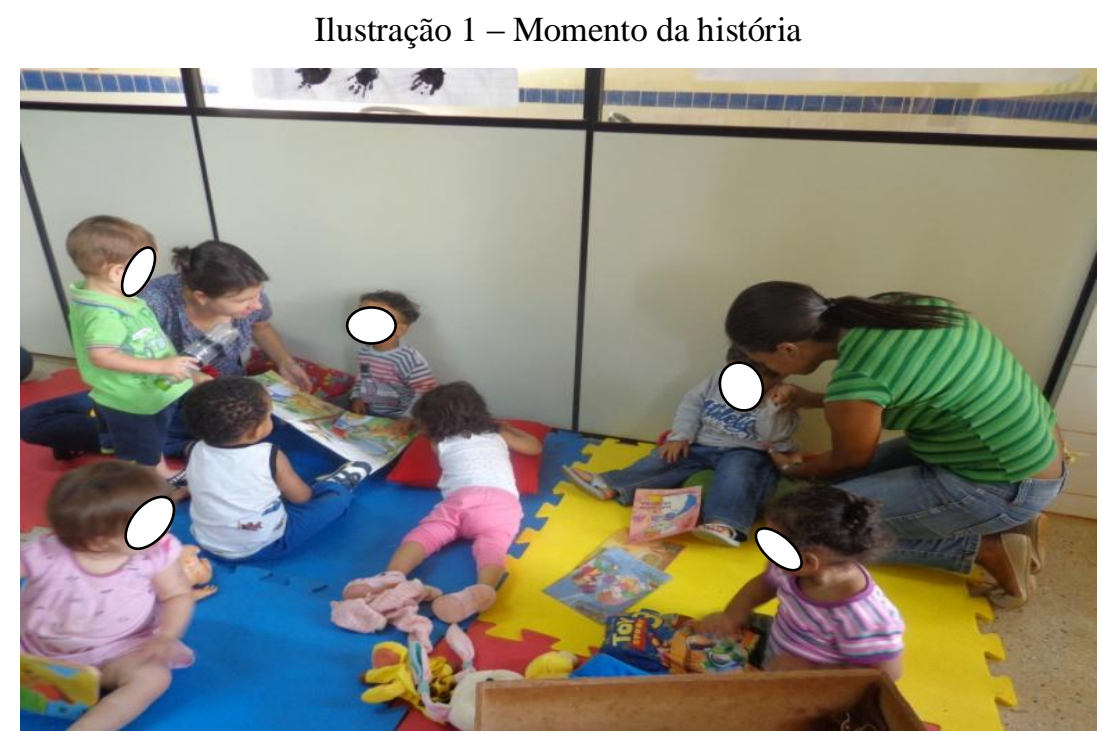

Fonte: Foto tirada por Lima (2012), organização dos dados: Rodrigues (2013) 


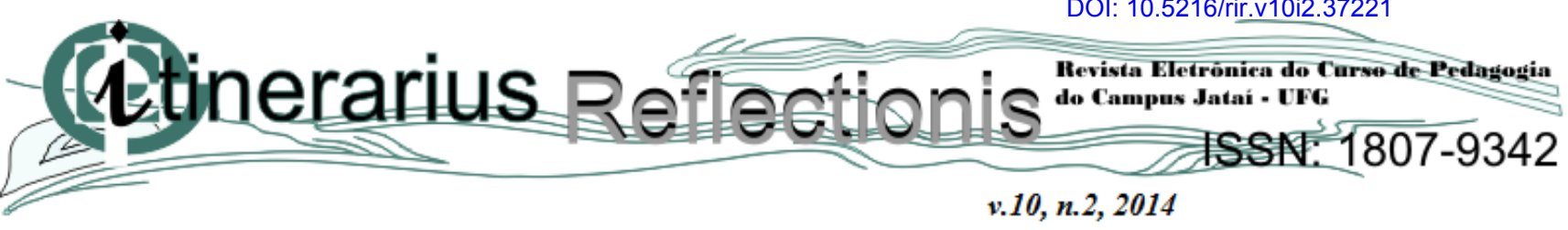

Sabemos da importância da literatura infantil no desenvolvimento pleno da criança. Segundo Ramos (2012):

\begin{abstract}
A participação em situações comunicativas e expressivas fornece à criança o desenvolvimento de suas capacidades lingüísticas. A leitura de textos escritos, a contação de histórias e a condução de relatos pelo professor se tornam interessantes vias de acesso ao repertório que é próprio da oralidade, ao contato com diferentes gêneros e portadores textuais, à riqueza advinda dos elementos da narrativa, ao gosto pela literatura e ao desenvolvimento de comportamentos leitores (p. 97).
\end{abstract}

Esse momento da leitura mediado pelo professor deve ser o mais prazeroso possível, propiciando um clima agradável e convidativo à escuta.

Contar histórias na Educação Infantil além de favorecer a relação afetiva da criança com o livro proporciona momentos de prazer, desperta a curiosidade, criatividade e contribui com a formação humana global da criança. Ao falarmos em formação humana, citamos Abramovich (1997), quando nos diz que: "Ah, como é importante para a formação de qualquer criança ouvir muitas, muitas histórias.... Escutá-las é o início da aprendizagem para ser um leitor, e ser leitor é ter um caminho absolutamente infinito de descoberta e de compreensão do mundo... (p. 16).

Assim, o incentivo à leitura deve se iniciar desde muito cedo, para que a criança desenvolva o gosto por esta prática que é tão importante para o seu crescimento e para a formação de sua oralidade, que nesta faixa etária ainda está se formando.

$\mathrm{Na}$ segunda proposta de trabalho, dedicamos ao incentivo dos órgãos do sentido propiciado por alguns tipos de texturas encontradas no ambiente externo da sala.

Neste dia levamos as crianças a um banho de sol no pátio da instituição. Nesse momento aproveitamos para estimular alguns órgãos dos sentidos nas crianças, como o de colocá-las na grama para sentirem a textura, despertando aí o tato; falamos sobre o quanto a grama estava verdinha por causa da chuva; mostramos algumas variedades de plantas que existiam na instituição, algumas folhas puderam até cheirar, propiciou-se aí o desenvolvimento olfato; mostramos às crianças alguns bichinhos existentes na grama como podemos ver nas imagens das ilustrações 2 e 3 . 


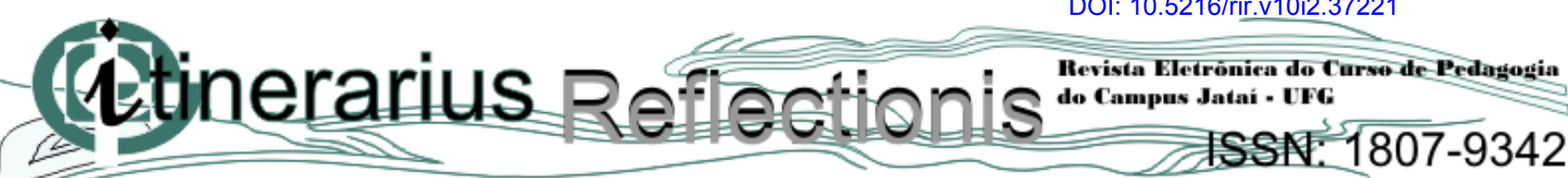 \\ $v .10, n .2,2014$}

Ilustração 2 - Crianças no pátio da instituição

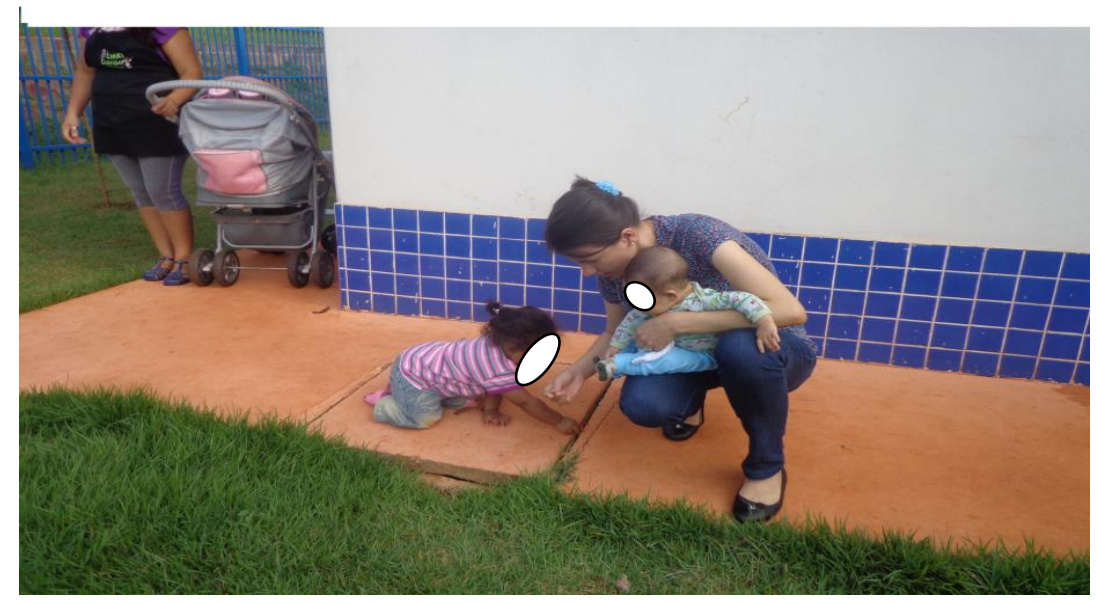

Fonte: Foto tirada por Lima (2012), organização dos dados: Rodrigues (2013)

Ilustração 3 - Crianças no pátio da instituição

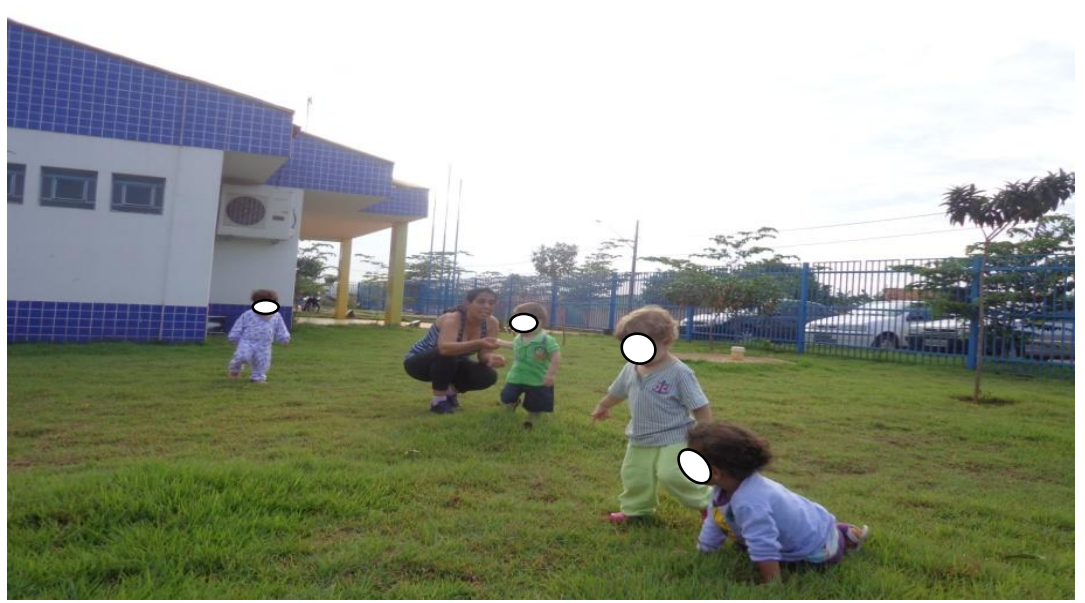

Fonte: Foto tirada por Lima (2012), organização dos dados: Rodrigues (2013)

Com essas atitudes, concordamos com Souza e Weiss (2008), quando as autoras afirmam que "para lidar com crianças dessa faixa etária é preciso construir vivências significativas, envolvendo exploração, com todos os sentidos" (p. 38). 


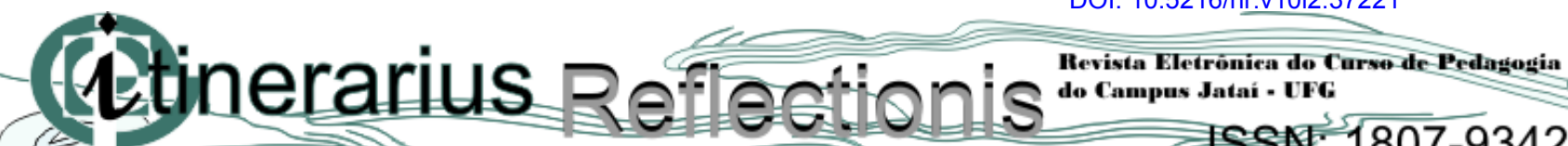 20. \\ v.10, n.2, 2014

Acreditamos na valorização e "importância da experimentação (que envolve o corpo inteiro: tocar, pegar, mexer, molhar, misturar, movimentar-se etc." (idem). E essas possibilidades nem sempre estão dispostas dentro da sala de aula, por isso o pátio foi pensado e planejado.

Nossa próxima proposta de trabalho foi o desenvolvimento corporal das crianças e relacionamento interpessoal. Para atingirmos nosso objetivo levamos as crianças para um banho de sol no pátio. Lá havia alguns brinquedos como escada, escorregador, túnel, bolas etc. conforme ilustração 4 .

\section{Ilustração 4 - Crianças no pátio da instituição com brinquedos}

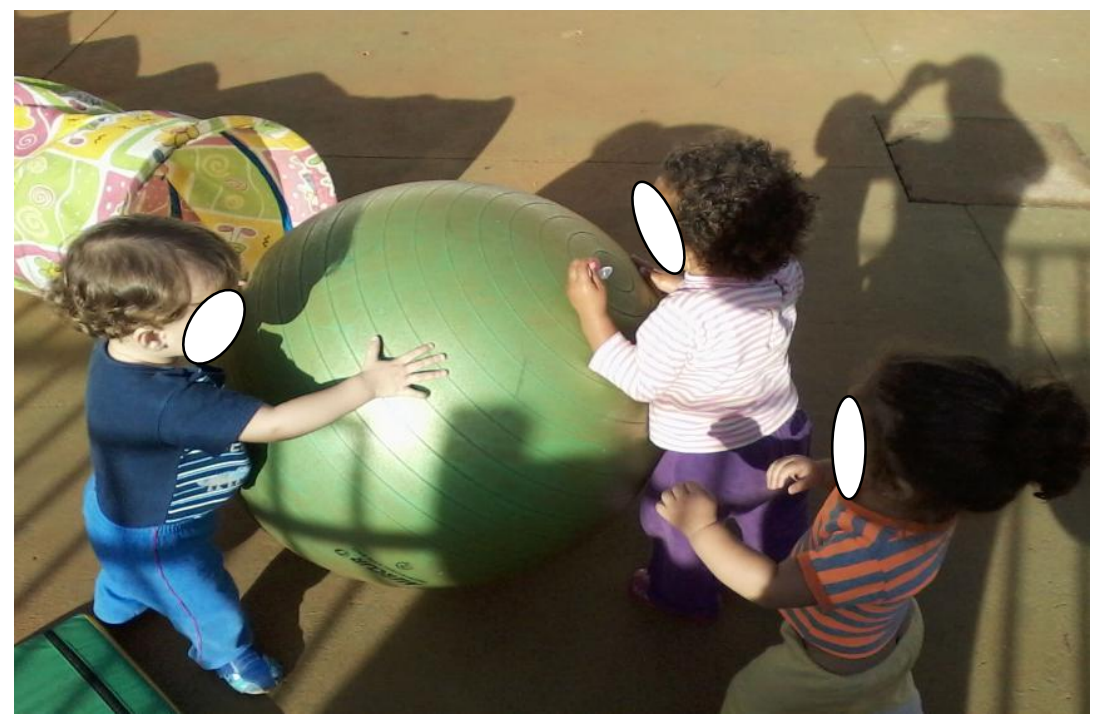

Fonte: Foto tirada por Pereira (2012).

Segundo Carvalho e Rubiano (2007):

Os ambientes devem fornecer oportunidades para as crianças andarem, correrem subirem, subirem, descerem e pularem com segurança, permitindo-lhes tentar, falhar e tentar novamente. Especialmente durante o período sensório-motor (três primeiros anos de vida), um ambiente ideal deveria oferecer oportunidades frequentes para a criança aprender a se mover e a controlar o próprio corpo no espaço, como: sentar, balançar o próprio corpo, engatinhar, saltar, correr, subir, pular, agarrar-se, pendurar-se curvar-se e virar-se (p. 110-111).

Esse momento foi aproveitado para trabalhar com as crianças diversos aspectos de relacionamento como: esperar a vez de participar, saber ouvir o colega, possibilitar trocas, dentre outros. Ou seja, a nossa preocupação sempre foi em relação ao 


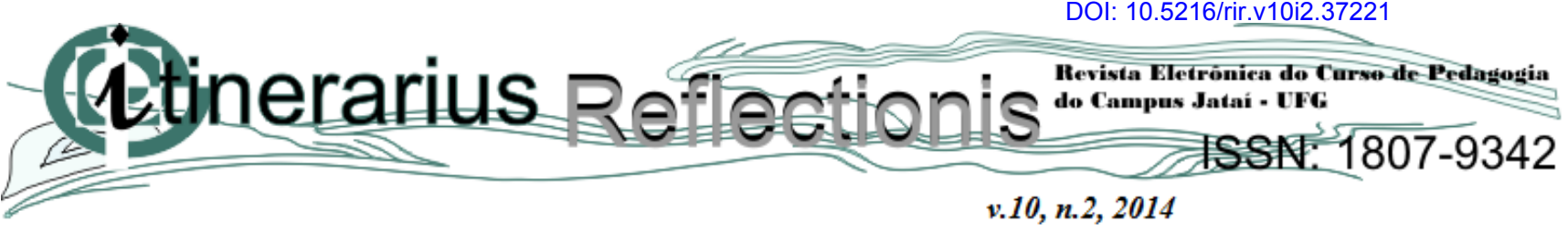

desenvolvimento do sujeito e vemos na brincadeira a nossa eterna aliada, pois afinal, estamos tratando de crianças as quais na maioria, ainda nem falam e os conflitos e confrontos entre seus pares são rotina em seus dia-a-dia. Mas que acima de tudo, sabemos que tais fatores são importantes e fazem parte do crescimento individual de cada um. De acordo com Horn (2004),

A confrontação com os companheiros lhe permite constatar que é uma entre outras crianças e que, ao mesmo tempo, é igual e diferente delas. [...] Elas necessitam de espaço para exercerem sua criatividade e para contestarem o que desaprovam. [...] Por isso, em um ambiente sem estímulos, no qual as crianças não possam interagir desde tenra idade umas com as outras, com os adultos e com objetos e materiais diversos, esse processo de desenvolvimento não ocorrerá em sua plenitude. [...] É fundamental a criança ter um espaço povoado de objetos com os quais possa criar, imaginar, construir e, em especial, um espaço para brincar. [...] É através da atividade de brincar que a criança se desenvolve. Somente nessa dimensão a brincadeira pode ser considerada uma atividade condutora que determina o desenvolvimento da criança (p. 17-20).

Devido ao fato de as crianças serem muito pequenas, algumas nem haviam desenvolvido a fala completamente, vários conflitos aconteceram, pois queriam todos utilizar o brinquedo ao mesmo tempo. Foi difícil manter o estabelecimento das regras no decorrer das brincadeiras. Mas permanecemos firmes em nossa proposta, pois sabíamos da importância desta para com o desenvolvimento de nossos objetivos. De acordo com Frazotto (2007), “trabalhar regras com as crianças é um exercício longo, que pede constância, e tenacidade. Mas fará nossas crianças capazes de conviver de forma saudável e gostosa com as diferenças entre as pessoas, respeitando-as em seus limites” (p. 175).

As atividades propostas neste dia foram desenvolvidas pensando na perspectiva de que a escola pode oferecer aos alunos, atividades que lhes oportunizem momentos de manifestações motoras no ambiente escolar, nos aspectos de esquema, imagem e consciência corporal.

Outra proposta de trabalho foi o desenvolvimento de atividades de texturas com as crianças. Levamos uma caixa surpresa na qual haviam caixas encapadas com diferentes materiais como: papeis, algodões, esponja de aço. Em algumas caixas colocamos objetos os quais emitiam sons para atrair a atenção das crianças. Cada caixinha tinha rosto referente a algum animal, objetos e pessoas. 


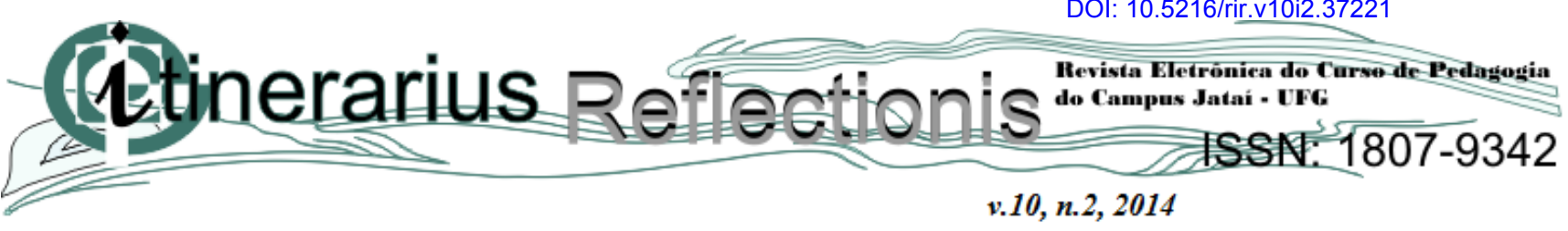

Ao desenvolvermos a atividade com texturas, percebemos que as caixinhas também poderiam ser usadas com outra função, neste caso, elas poderiam contar histórias. Silva, Costa e Mello (2009), afirmam que:

\begin{abstract}
Para o educador variar na sua escolha de como e o que contar, podemos criar e adaptar as historias de muitas maneiras e uma delas são as caixas. É, caixas que contam contos, caixas que contam histórias. Podem ser grandes ou pequenas. Quadradas ou redondas. Devem ter cenários coloridos, castelos e mares bravos, rios que levam a todos os lugares (p. 96).
\end{abstract}

Essa proposta que desenvolvemos visava alguns objetivos como: fazer com que as crianças reconhecessem os diferentes tipos de textura; valorizar o tato; enriquecer o imaginário infantil. De acordo com Arce e Silva (2009), é tarefa do educador estimular os diversos sentidos da criança, verbalizando as ações. Segundo as autoras, "um trabalho de estimulação que é necessária e que demanda, para que se possa qualificar seus resultados, ser planejada detalhadamente, objetivando desenvolvimento integral da criança” p. 179.

Assim, percebemos a responsabilidade do educador de EI em conhecer as necessidades específicas de cada fase da criança no desenvolvimento de suas habilidades, ampliando o seu repertório de ações e assumindo papel de mediador no processo de aquisição de conhecimentos por meio de interações significativas.

\title{
4. CONSIDERAÇÕES FINAIS
}

Ao final deste trabalho concluímos que os bebês interpretam o mundo de modo próprio e peculiar, e a partir das relações que estabelecem com o adulto, é que constroem sentido sobre tudo que os rodeiam.

O ambiente pedagógico do berçário se configura como um espaço gerador do desenvolvimento afetivo e cognitivo da criança, o qual fortalece a desenvoltura social dos pequenos por meio da participação ativa nas atividades que lhes são dirigidas.

Com a proposta de trabalho realizada com os bebês, percebemos as múltiplas formas de expressão, explorações e oportunidades de interações com as quais se comunicavam tanto entre eles quanto com os adultos (educadoras). Assim, revelavam valiosos aspectos sobre suas potencialidades e traziam informações necessárias para a configuração de práticas educativas construídas com e para eles. 


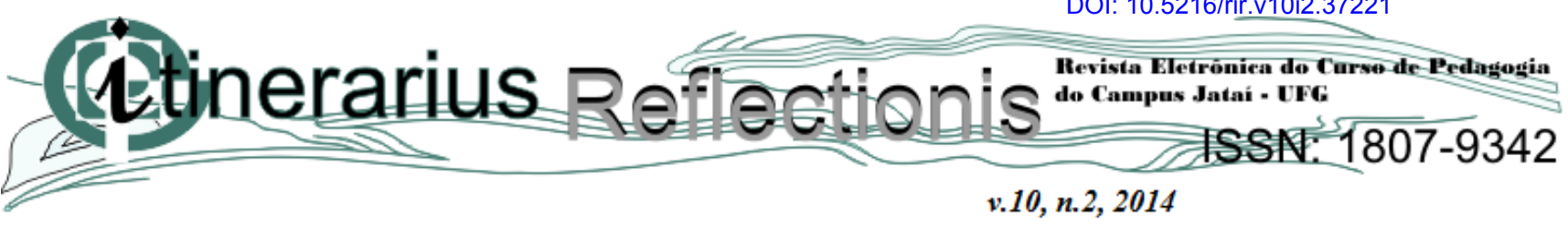

Pautamos nosso trabalho baseado em uma proposta que foi sustentada na pesquisa, na experimentação e na vivência com diferentes materiais e espaços. Assim, possibilitamos múltiplas formas de expressão e aprendizagem por parte dos bebês.

Por fim, destacamos a importância de um trabalho sério e intencional por parte do professor que possua conhecimento teórico e prático para intervir na vida da criança, desde a mais tenra idade, apresentando-a ao mundo natural humanizado.

\section{REFERÊNCIAS}

ABRAMOVICH, Fanny. Literatura infantil: gostosuras e bobices. 5. ed. São Paulo: Scipione, 1997. (Pensamento e ação no magistério)

ARCE, Alessandra; SILVA, Janaina Cassiano. É possível ensinar no berçário? O ensino como eixo articulador do trabalho com bebês ( 6 meses a 1 ano de idade). In: ARCE, Alessandra; MARTNS, Lígia M. (orgs). Ensinando aos pequenos de zero a três anos. Campinas, SP: Alínea, 2009. p. 163-185.

CARVALHO, Mara I. Campos de; RUBIANO, Márcia R. Bonagamba. Organização do Espaço em Instituições Pré-Escolares. In: OLIVEIRA, Zilma de Moraes Ramos de (org.). Educação infantil: muitos olhares. 5. ed. São Paulo: Cortez, 2001. p. 107-130.

FRAZOTTO, Lenice. Pensando a disciplina: trabalhar regras é mais importante do que uma classe quietinha. In: FERREIRA, Maria Clotilde Rossetti. Os fazeres na educação infantil. São Paulo: Cortez, 2009.

HORN, Maria da Graça Souza. Sabores, cores, sons, aromas: a organização dos espaços na educação infantil. Porto Alegre: Artmed, 2004. p. 13-21.

LIMA, Laís Leni O. As muitas faces do trabalho que se realiza na educação infantil. 2010. Tese (Doutorado em Educação) - Faculdade de Educação, Universidade Federal de Goiás, Goiânia, 2010.

LINO, Dulcimarta Lemos. Música é... cantar, dançar... e brincar! Ah, tocar também! In: CUNHA, Susana Rangel Vieira da (org.). Cor, som e movimento: a expressão plástica, musical e dramática no cotidiano da criança. Porto Alegre: Mediação, 1999. p. 59-92.

RAMOS, Tacyana Karla Gomes. Ampliando recursos expressivos. In: RAMOS, Tacyana Karla Gomes; ROSA, Ester Calland de Sousa (Orgs.). Os saberes e as falas de bebês e suas professoras. 2. ed. rev. e ampl. Belo Horizonte: Autêntica, 2012. p. 92-111. 


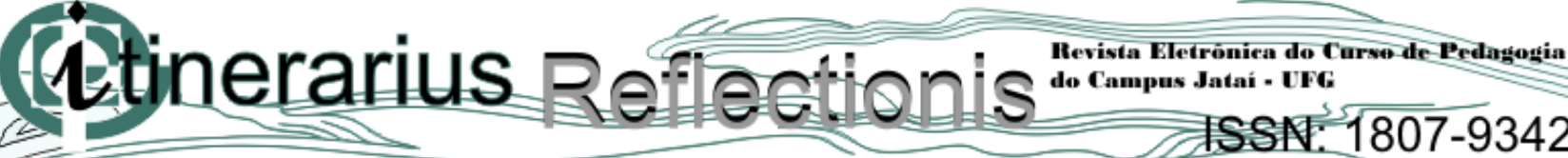 \\ v.10, $n .2,2014$}

SILVA, Lésia M. Fernandes; COSTA, Edna Ap. A. da e MELLO, Ana Maria. Os contos que as caixas contam. In: ROSSETTI-FERREIRA, Maria Clotilde et. al. Os fazeres na educação infantil. Ribeirão Preto SP: Cortez, 2009.

SOUZA, Andressa Celis ; WEISS, Vanilda. Aprendendo a ser professora de bebês. In: OSTETTO, Luciana Esmeralda (Org.). Educação Infantil: Saberes e fazeres da formação de professores. Campinas, SP: Papirus, 2008. p. 33-48. 